\title{
The Occurrence and Spatial Distribution of Organophosphorous Pesticides in Chinese Surface Water
}

\author{
Jijun Gao $\cdot$ Linghua Liu $\cdot$ Xiaoru Liu $\cdot$ \\ Huaidong Zhou $\cdot$ Jin Lu $\cdot$ Shengbiao Huang $\cdot$ \\ Zijian Wang
}

Received: 20 February 2008 / Accepted: 11 November 2008/Published online: 2 December 2008

(C) Springer Science+Business Media, LLC 2008

\begin{abstract}
The organophosphorous pesticides (OPPs) contaminations have been reported to occur in some Chinese waters. To describe the contamination status and the spatial distribution of OPPs in the surface water throughout China, samples were collected from over 600 sites located in the surface water of seven major river basins and three main internal rivers drainage areas during 2003 and 2004. The surface water samples were analyzed for the representative OPPs including dichlorvos, demeton, dimethoate, methyl parathion, malathion and parathion. In general, the most frequently detected compound was dichlorvos and demeton, being detected in $89.1 \%$ of samples (mean $=17.8 \mathrm{ng} / \mathrm{L}$; range $<1.4-1,552.0 \mathrm{ng} / \mathrm{L}$ ) for dichlorvos, and $78.2 \%$ of samples $($ mean $=35.4 \mathrm{ng} / \mathrm{L} ;$ range $<1.5-2,560.0 \mathrm{ng} / \mathrm{L}$ ) for demeton. While the detection frequencies of the dimethoate, methyl parathion, malathion, and parathion were all less than $50 \%$ in all the surface water samples. Measured concentrations for the six compounds were low and rarely exceed the environment quality standard for surface water of China. The six OPPs compounds were more frequently detected at much higher concentrations in the rivers of north China compared with those of south China.
\end{abstract}

J. Gao $\cdot$ S. Huang $\cdot$ Z. Wang $(\bowtie)$

State Key Laboratory of Environmental Aquatic Chemistry, Research Center for Eco-Environmental Sciences, Chinese Academy of Sciences, P.O. Box 2871, 18 Shuangqing Rd, Haidian District, Beijing 100085, China

e-mail: wangzj@rcees.ac.cn

J. Gao $\cdot$ L. Liu $\cdot$ X. Liu $\cdot$ H. Zhou $\cdot$ J. Lu

Department of Water Environment, China Institute of Water Resources and Hydro-Power Research, Yuyuantan Science and Technology Garden, Haidian District, Beijing 100038, China
The results of this investigation indicate that OPPs contamination in the Yellow River, Huaihe River, Liaohe River, and Haihe River basins of north China should be of particular concern. When compared with other regions of the world, it appears that the Chinese surface water is some moderately polluted by dimethoate, methyl parathion, malathion, parathion and contaminated by dichlorvos and demeton in certain degree.

Keywords Surface water - China - Dichlorvos . Malathion · Dimethoate

Over the past few decades, several hundred pesticides of different chemical nature are currently used for agricultural purposes all over the world. It is well known that most of the applied pesticides are subject to many transport and conversion products. Thus, they do not remain at their target site but often enter aquatic environment via soil percolation, air drift or surface runoff, the surface water contamination may have ecotoxicological effects for aquatic flora and fauna as well as for human health if used for public consumption (Forney and Davis 1981; Mulla and Mian 1981; Leonard 1988; Miyamoto et al. 1990), affecting abundance and diversity of non-target species producing complex effects on the ecosystems and altering tropic interactions (Rand et al. 1995). Because of their widespread use, they are detected in various environmental matrices, such as soil, water and air. Pesticides are divided into many classes, of which the most important is organophosphorous compounds. OPPs are among the most potent insecticides known and have been used throughout the world to control pests in agricultural crops, forests, and wetlands for more than four decades (Smith 1987). Their 
wide use is due to high toxicity and rapid environmental degradation (Eto 1974). Unfortunately, OPPs lack target specificity and can cause severe and persistent population effects on aquatic non-target species, particularly invertebrates (Fulton and Key 2001; Schulz and Liess 1999; Christopher et al. 2001).

As the world's second largest pesticide manufacturer, it has been estimated that China produced 203,000381,000 metric tons annually of technical-grade pesticides between 1985 and 1996(Huang et al. 2000). The magnitude of contamination of these pesticides pollutants in surface water, however, had not been systematically investigated at the national scale of China. In order to determine the contamination status and the spatial distribution of organophosphorous pesticides in China's surface water, methyl parathion, malathion, parathion, dichlorvos, demeton and dimethoate were chosen as the representative compounds for analysis. Because the six compounds had been used widely in China as the main organophosphorous pesticides, and the analysis results of them can more correctively characterize the contamination status of organophosphorous pesticides, adding their the toxicity and ecological effects, the six compounds were chosen as representative to characterize the pollution status of organophosphorous pesticides in Chinese surface water. Samples collected from over 600 sites in seven major rivers basins and three internal rivers drainage areas were analyzed for methyl parathion, malathion, parathion, dichlorvos, demeton and dimethoate.

\section{Materials and Methods}

Little data were available on the occurrence of methyl parathion, malathion, parathion, dichlorvos, demeton and dimethoate at the outset of this investigation, therefore, the sampling sites was chosen randomly along the individual river basin. The 623 sites sampled during 2003-2004 (Fig. 1), including 217 reservoirs and 406 rivers and lakes. Samples were collected from the seven major river basins, including the Yangtze River basin, the Yellow River basin, the Pearl River basin, the Songhua River basin, the Liaohe River basin, the Haihe River basin and the Huaihe River basin. Samples were also collected from rivers in southeast, northwest and southwest internal rivers drainage areas. The global positioning system (GPS) was used to locate the sampling positions. The sites map distribution is shown in Fig. 1.

All samples were collected by hydrological bureau personnel using consistent protocols and procedures designed to obtain a representative sample using standard depth and width integrating techniques (Shelton 1994). At each site, a composite water sample was collected from about 4 to 6 vertical profiles. Water was passed through a $0.45 \mu \mathrm{m}$, baked, glass-fiber filter in the field where possible, or else filtration was conducted in the laboratory. Water samples for chemical analysis were stored in precleaned-amber, glass bottles and collected in duplicate. The duplicate samples were used for backup purposes (incase of breakage of the primary sample) and for laboratory
Fig. 1 Map of sampling sites distribution

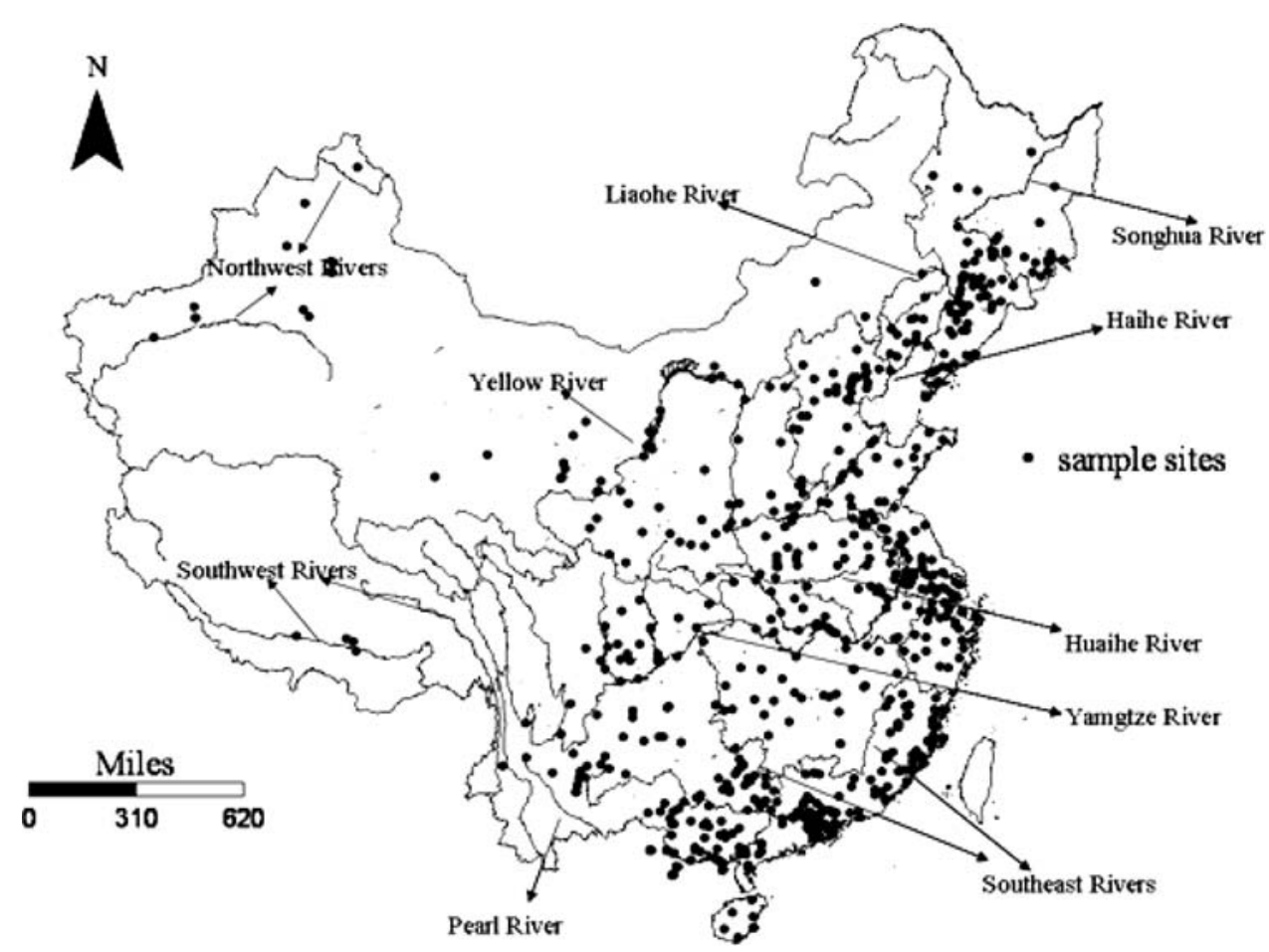


replicates. Following collection, samples were immediately chilled and sent to the laboratory.

Aliquots of the sample $(5.0 \mathrm{~L})$, which were filtered through a $0.45 \mu \mathrm{m}$ glass fiber membrane under vacuum and then surrogates (simazina- $\mathrm{D}_{5}$ ) were added before extraction, were extracted by solid phase extraction (SPE) following published procedures (Zhou et al. 2002; Zhang et al. 2002a, b). Briefly, the SPE cartridges were first conditioned with $10 \mathrm{~mL}$ of methanol followed by $2 \times 5 \mathrm{~mL}$ of deionized water. Water samples were passed through the cartridges at a flow rate of $6 \mathrm{~mL} / \mathrm{min}$ under vacuum and OPPs are then eluted by passing $10 \mathrm{~mL}$ of ethyl acetate through the cartridge, making it possible to pass these compounds from the water phase to an organic phase, residual water was removed by anhydrous $\mathrm{Na}_{2} \mathrm{SO}_{4}$. The extracts obtained were concentrated with a $\mathrm{N}_{2}$ flow until an approximate volume of $0.5 \mathrm{~mL}$ is reached, Anthracene deuterade $\left(\mathrm{D}_{10}\right)$ (SUPELCO) is then added to extract for subsequent quantification of OPPs present in the samples. These extracts are analyzed by GC/MS.

All solvents used for sample processing and analysis (ethyl acetate, hexane, acetone methanol) were of HPLC grade. Deionized water was prepared using a Milli-Q system (Millipore, Watford). Chemical standards of OPPs were obtained from Supelco. Working standards were prepared in ethyl acetate and the internal standard Anthracene deuterade $\left(\mathrm{D}_{10}\right)$ was added to each working standard. These solutions were further diluted with ethyl acetate to prepare calibration solutions.

An Agilent 6890 GC coupled to a model 5973N MS was used for methyl parathion, malathion, parathion, dichlorvos, demeton and dimethoate analysis. Peak confirmation was achieved with an Agilent 6890 GC coupled to a model $5973 \mathrm{~N}$ MS detector in selected ion mode. The capillary column used was HP-5MS $(30 \mathrm{~m} \times 0.25 \mathrm{~mm}$ i.d. $\times$ $0.25 \mu \mathrm{m}$ film thickness). All the instruments and capillary column were from Agilent company of America. The carrier gas was helium for MS. The inlet was heated to $220^{\circ} \mathrm{C}$. The GC column temperature was programmed as follows: initially at $60^{\circ} \mathrm{C}$ (equilibrium time $1 \mathrm{~min}$ ), increased to $140^{\circ} \mathrm{C}$ at the rate of $10^{\circ} \mathrm{C} / \mathrm{min}$, then to $230^{\circ} \mathrm{C}$ at $5^{\circ} \mathrm{C} / \mathrm{min}$ before reaching at $260^{\circ} \mathrm{C}$ at the rate of $10^{\circ} \mathrm{C} / \mathrm{min}$ and then held for $10 \mathrm{~min}$. The MS temperature was set at $280^{\circ} \mathrm{C}$ and the electron impact energy was $70 \mathrm{eV}$.

The residue levels of OPPs were quantitatively determined by the internal standard method using peak area. The method detection limits (MDLs) of OPPs were taken to be 3:1 signal versus noise value $(\mathrm{S} / \mathrm{N})$. For every set of 10 samples, a procedural blank and a spiked sample with standards were run to check for the interference and crosscontamination. Table 1 illustrated the Mean recoveries, MDLs and relative standard derivation (RSD\%) of the method. The MDLs ranged from $0.8 \mathrm{ng} / \mathrm{L}$ for malathion to
Table 1 Recoveries, method detection limits (MDLs), and the relative standard derivation (RSD) of the analytical procedure

\begin{tabular}{llll}
\hline Pesticides & $\begin{array}{l}\text { Recovery } \\
(\%)\end{array}$ & $\begin{array}{l}\text { MDLs } \\
(\mathrm{ng} / \mathrm{L})\end{array}$ & $\begin{array}{l}\text { RSD } \\
(\%) \\
(\mathrm{n}=6)\end{array}$ \\
\hline $\begin{array}{l}\text { Dichlorvos } \\
\text { Demeton }\end{array}$ & $68.4-89.8$ & 1.4 & 7.2 \\
$\begin{array}{l}\text { Dimethoate } \\
\text { Methyl }\end{array}$ & $64.6-88.7$ & 1.5 & 6.3 \\
$\quad$ parathion & $62.4-90.3$ & 1.3 & 2.5 \\
Malathion & $76.5-101.6$ & 0.9 & 6.3 \\
Parathion & $70.8-102.4$ & 0.9 & 4.2 \\
\hline
\end{tabular}

$1.5 \mathrm{ng} / \mathrm{L}$ for demeton. The spiked recoveries of OPPs using $1 \mathrm{ng}$ of composite standards were in the range of $64.6 \%$ $102.4 \%$ with RSD\% values ranging from $2.5 \%$ to $7.2 \%$. These parameters confirmed the suitability of the analytical protocols. A field quality assurance protocol was used to determine the effect, if any, of field equipment and procedures on the concentrations of OPPs in water samples. Field blanks, made from laboratory-grade organic free water, were submitted for about $5 \%$ of the sites and analyzed for OPPs. Field blanks were subject to the same sample processing, handling, and equipment as the water samples.

Values for OPPs lower than the method detection limits $(<\mathrm{MDL})$ were substituted with zero prior to statistical analysis. To detect the difference of OPPs concentrations between the north China and south China, the student t-test was employed in this study. Software from Excel Statistics was used in this study.

\section{Results and Discussion}

One or more OPPs were found in $91.2 \%$ of the 623 sample sites sampled for this study. The reason of the high overall frequency of detection for the OPPs is likely that the six compounds chosen were widely used in China as the main organophosphorous pesticides. In all the surface water samples collected, the detection rates of dichlorvos, demeton, dimethoate, methyl parathion, malathion and parathion were $89.1 \%, 78.2 \%, 37.0 \%, 29.7 \%, 43.5 \%$ and $28.6 \%$, respectively (Tables 2,3 ). From the data results, it should be known that the detection rate of dichlorvos was the highest and that of the parathion was the lowest. The mean values of the dichlorvos and demeton were $17.8 \mathrm{ng} / \mathrm{L}$ and $35.4 \mathrm{ng} / \mathrm{L}$, with a concentration range from $<1.4$ to $1,552.0 \mathrm{ng} / \mathrm{L}$ for dichlorvos and from $<1.5$ to $2,560.0 \mathrm{ng} / \mathrm{L}$ for demeton. The detection rates of the other four compounds were less than $50 \%$, so the statistical mean values can not be achieved. Among the six organophosphorous pesticides, the detection frequencies of dichlorvos (89.1\%) and demeton $(78.2 \%)$ were the highest, Which indicated 
Table 2 The summary results of dichlorvos, demeton and dimethoate concentration statistical analysis

\begin{tabular}{|c|c|c|c|c|c|c|c|c|c|c|c|c|c|}
\hline \multirow[t]{2}{*}{ Basins } & \multirow[t]{2}{*}{ Sample number } & \multicolumn{4}{|c|}{ Dichlorvos } & \multicolumn{4}{|c|}{ Demeton } & \multicolumn{4}{|c|}{ Dimethoate } \\
\hline & & Rate $\%$ & Min & Mean & $\operatorname{Max}$ & Rate \% & Min & Mean & $\operatorname{Max}$ & Rate \% & Min & Mean & Max \\
\hline Songhuajiang River & 40 & 17.5 & $<1.4$ & - & 20.0 & 17.5 & $<1.5$ & - & 110.0 & 22.5 & $<1.3$ & - & 180.0 \\
\hline Liaohe River & 58 & 70.7 & $<1.4$ & 14.5 & 70.0 & 70.7 & $<1.5$ & 122.1 & $2,560.0$ & 44.8 & $<1.3$ & - & 480.0 \\
\hline Haihe River & 39 & 100 & 10.0 & 25.6 & 50.0 & 100.0 & $<1.5$ & 70.8 & 50.0 & 66.7 & $<1.3$ & 42.8 & 220.0 \\
\hline Yellow River & 50 & 100 & 10.0 & 40.7 & 140.0 & 98.0 & $<1.5$ & 78.9 & 230.0 & 68.0 & $<1.3$ & 91.0 & $2,660.0$ \\
\hline Yangtse River & 150 & 100 & 2.0 & 17.9 & $1,552.0$ & 92.7 & $<1.5$ & 17.5 & 254.0 & 26.0 & $<1.3$ & & 16.0 \\
\hline Huaihe River & 39 & 100 & 2.0 & 25.2 & 140.0 & 92.3 & $<1.5$ & 41.5 & 200.0 & 59.0 & $<1.3$ & 34.6 & 280.0 \\
\hline Pearl River & 150 & 91.3 & $<1.4$ & 5.6 & 24.0 & 74.0 & $<1.5$ & 9.1 & 124.0 & 25.3 & $<1.3$ & & 28.8 \\
\hline Southeast drainage area rivers & 74 & 97.3 & $<1.4$ & 9.4 & 86.0 & 75.7 & $<1.5$ & 20.7 & 358.0 & 23.0 & $<1.3$ & - & 9.6 \\
\hline Northwest drainage area rivers & 18 & 100 & 10.0 & 27.6 & 70.0 & 100.0 & 20.6 & 104.6 & 320 & 44.4 & $<1.3$ & - & 110.0 \\
\hline Southwest drainage area rivers & 5 & 0 & - & - & - & 0 & $<1.5$ & - & - & 0 & $<1.3$ & - & - \\
\hline North China & 244 & 80.3 & $<1.4$ & 22.4 & 140.0 & 78.3 & $<1.5$ & 73.2 & 2,560 & 52.0 & $<1.3$ & 48.0 & $2,660.0$ \\
\hline South China & 379 & 94.7 & $<1.4$ & 11.1 & $1,552.0$ & 80.7 & $<1.5$ & 14.6 & 358 & 24.8 & $<1.3$ & - & 28.8 \\
\hline Overall China & 623 & 89.1 & $<1.4$ & 17.8 & $1,552.0$ & 78.2 & $<1.5$ & 35.4 & $2,560.0$ & 37.0 & $<1.3$ & - & $2,660.0$ \\
\hline
\end{tabular}

Table 3 The summary results of methyl parathion, malathion and parathion statistical analysis

\begin{tabular}{|c|c|c|c|c|c|c|c|c|c|c|c|c|c|}
\hline \multirow[t]{2}{*}{ Basins } & \multirow[t]{2}{*}{ Sample number } & \multicolumn{4}{|c|}{ Methyl parathion } & \multicolumn{4}{|c|}{ Malathion } & \multicolumn{4}{|c|}{ Parathion } \\
\hline & & Rate $\%$ & Min & Mean & Max & Rate $\%$ & Min & Mean & Max & Rate $\%$ & Min & Mean & Max \\
\hline Songhuajiang River & 40 & 20.0 & $<0.9$ & - & 130.0 & 17.5 & $<0.8$ & - & $1,070.0$ & 17.5 & $<0.9$ & - & 30.0 \\
\hline Liaohe River & 58 & 70.7 & $<0.9$ & 25.3 & 120 & 70.7 & $<0.8$ & 59.1 & 180 & 72.4 & $<0.9$ & 14.6 & 40.0 \\
\hline Haihe River & 39 & 100.0 & 10.0 & 32.1 & 160 & 100.0 & 10.0 & 49.5 & 130 & 100.0 & 10.0 & 19.0 & 40.0 \\
\hline Yellow River & 50 & 98.0 & $<0.9$ & 46.9 & 480 & 100.0 & 10.0 & 101.2 & $1,290.0$ & 98.0 & $<0.9$ & 23.6 & 150 \\
\hline Yangtse River & 150 & 4.0 & $<0.9$ & - & 20.0 & 21.3 & $<0.8$ & & 540.0 & 5.3 & $<0.9$ & & 20.0 \\
\hline Huaihe River & 39 & 46.2 & $<0.9$ & - & 60.0 & 64.1 & $<0.8$ & 36.5 & 229 & 56.4 & $<0.9$ & 8.3 & 30.0 \\
\hline Pearl River & 150 & 1.3 & $<0.9$ & - & 3.1 & 24.7 & $<0.8$ & & 216 & 4.0 & $<0.9$ & & 2.0 \\
\hline Southeast drainage area rivers & 74 & 4.0 & $<0.9$ & - & 16.4 & 28.4 & $<0.8$ & - & 262 & 6.8 & $<0.9$ & - & 2.0 \\
\hline Northwest drainage area rivers & 18 & 100.0 & 10.0 & 16.9 & 50.0 & 100.0 & 10 & 51.8 & 180.0 & 94.4 & $<0.9$ & 17.2 & 30.0 \\
\hline Southwest drainage area rivers & 5 & 0 & $<0.9$ & - & $<0.9$ & 0 & $<0.8$ & - & - & 0 & $<0.9$ & - & $<0.9$ \\
\hline North China & 244 & 71.3 & $<0.9$ & 25.7 & 480 & 74.6 & $<0.8$ & 59.5 & $1,290.0$ & 72.1 & $<0.9$ & 14.6 & 150 \\
\hline South China & 379 & 2.9 & $<0.9$ & - & 20.0 & 23.7 & $<0.8$ & - & 540 & 5.0 & $<0.9$ & - & 20.0 \\
\hline Overall China & 623 & 29.7 & $<0.9$ & - & 480.0 & 43.5 & $<0.8$ & - & $1,290.0$ & 28.6 & $<0.9$ & - & 150.0 \\
\hline
\end{tabular}

that the two compounds were the prevalent organophosphorous pesticides pollutants in Chinese surface water. In addition, the measured concentrations of six compounds were generally low (mean detectable concentrations generally $<1 \mu \mathrm{g} / \mathrm{L}$, Tables 2, 3), without any compound exceeding drinking water guidelines, health advisories, or aquatic-life criteria (Tables 2, 3).

As the prevalent organophosphorous pesticides pollutants in Chinese surface water, the similar spatial distribution occurred for the dichlorvos and demeton. For the seven major river basins and three internal rivers drainage areas, the detection rates of dichlorvos and demeton were also from $0 \%$ to $100 \%$. Among different river basins, the mean concentration of dichlorvos in the Pearl River basin was the lowest (mean $=5.6 \mathrm{ng} / \mathrm{L}$ ) and that in the Yellow River basin was the highest (mean $=40.7 \mathrm{ng}$ / $\mathrm{L})$, the second highest mean level occurred in the northwest region $($ mean $=27.6 \mathrm{ng} / \mathrm{L}$ ), followed by the Haihe River $($ mean $=25.6 \mathrm{ng} / \mathrm{L})$, Huaihe River $($ mean $=25.2 \mathrm{ng} / \mathrm{L})$ and Yangtze River $($ mean $=17.9 \mathrm{ng} / \mathrm{L})$. While for the demeton, the mean concentration in the Pearl River basin was also the lowest (mean $=9.1 \mathrm{ng} / \mathrm{L}$ ) and that in the Liaohe River basin was the highest (mean $=122.1 \mathrm{ng} / \mathrm{L}$ ), the second highest mean level occurred in the northwest internal rivers $($ mean $=104.6 \mathrm{ng} / \mathrm{L})$, followed by the Yellow River basin $($ mean $=78.9 \mathrm{ng} / \mathrm{L})$, the Haihe River $($ mean $=70.8 \mathrm{ng} / \mathrm{L})$ and the Huaihe River (mean $=$ $41.5 \mathrm{ng} / \mathrm{L})$. In addition, the dichlorvos and demeton detection rate of north China (including Songhuajiang River, Liaohe River, Haihe River, Yellow River, Huaihe 
River, and northwest drainage area rivers) was $80.3 \%$ and $78.3 \%$, with the mean value $22.4 \mathrm{ng} / \mathrm{L}$ and $73.2 \mathrm{ng} / \mathrm{L}$, respectively. While the dichlorvos and demeton detection rates of south China (including Yangtse River, Pearl River, southeast drainage area rivers and southwest drainage area rivers) was $94.7 \%$ and $80.7 \%$, with the mean value $11.1 \mathrm{ng} / \mathrm{L}$ and $14.6 \mathrm{ng} / \mathrm{L}$. According to the concentration distribution results, the river basins with high dichlorvos and demeton concentrations mainly occurred in north China, Which suggests that the high levels of the two compounds in surface water were mainly present in areas of north China, while the more polluted sites of the south China mainly occurred in the Yangtze River. The statistical analysis result showed a significant difference between the north China rivers and the south China rivers concentrations $(t=1.65, p<0.001)$.

The methyl parathion, malathion, parathion, and dimethoate detection frequencies were less than the dichlorvos and demeton detection rates, and there was also similar spatial distribution trend characteristics to the dichlorvos and demeton. For the dimethoate, there were only the Haihe River (66.7\%), Yellow River (68.0\%) and Huaihe River $(59.0 \%)$ basins with the detection frequencies higher than $50 \%$, and the three basins mainly occurred in the north China. The dimethoate detection rate of north China was $52.0 \%$, with a mean value $48.0 \mathrm{ng} / \mathrm{L}$, while detection rate of south China was only $24.8 \%$. The dimethoate concentration distribution results suggested that the river basins with high dimethoate concentrations mainly occurred in north China, the similar situations occurred in the methyl parathion, malathion, and parathion. The river basins with the methyl parathion detection higher than $50 \%$ were Liaohe River, Haihe River, Yellow River, and the northwest drainage area rivers of the north China, the detection rates of the other river basins were all less than $50 \%$. While for the malathion and parathion, the detection frequencies of Liaohe River, Haihe River, Yellow River, Huaihe River, and the northwest drainage area rivers of north China were all higher than $50 \%$, the other river basins with the detection rates less than $50 \%$. The detection rates of methyl parathion, malathion, parathion, and dimethoate in north China were $71.3 \%, 74.6 \%, 14.6 \%$ and $52.0 \%$, respectively, much higher than that of methyl parathion, malathion, parathion and dimethoate in south China $(2.9 \%, 23.7 \%, 5.0 \%$ and $24.8 \%$, respectively). From the concentration distribution results, it should be known that the river basins with high methyl parathion, malathion, parathion and dimethoate concentrations mainly occurred in north China, which suggests that the high levels of the four compounds in surface water were mainly present in areas of north China.

Due to their efficiency and inexpensiveness, OPPs had been widely used in agriculture for crop protection and fruit tree treatment as substitute for OCPs. The OPPs have occupied the dominant position in production and use in China since the use of OCPs such as DDT and HCH was banned in 1983. There are over 20 kinds of OPPs in production and it was reported that, 0.11 million tons of OPPs were used in 1989 , occupying $52.8 \%$ of the total usage of pesticides and $77 \%$ of the total usage of insecticide in China (Pan et al. 1997). It was obvious that dichlorvos, demeton had higher occurrence and concentration than other OPPs because of a large amount of application loads. It was reported that in 2002, over 10 thousand tons of dichlorvos, trichlofon and demeton were employed in China, respectively, which were far more than other OPPs usage (Hua and Shan 1999). Furthermore, because of the acute toxicity for human being and other endotherm, parathion and methyl parathion were gradually reduced in use. In 2004, parathion and methyl parathion was decreased by $22.51 \%$ and $14.52 \%$ in usage compared to in 2003 (Shao and Su 2004). In January 2004, the registration of five highly toxic OPPs including parathion and methyl parathion was stopped and from January. 2007, their use will be completely forbidden in China (Tang et al. 2004). This can give a good explanation of the lower concentration and occurrence of them.

Another conclusion drawn from the data was that there was a significant difference in concentration between the north China and the south China surface water and the high levels of OPPs in surface water were mainly present in areas of north China. The highest concentrations of OPPs were $1,552.0 \mathrm{ng} / \mathrm{L}$ for dichlorvos in Yangtze River, 2,560.0 ng/L for demeton in Liaohe River, 2,660.0 ng/L for dimethoate in Yellow River, $480.0 \mathrm{ng} / \mathrm{L}$ for methylparathion in Yellow River, 1,290.0 ng/L for malathion in Yellow River and $150.0 \mathrm{ng} / \mathrm{L}$ for parathion in Yellow River. Except for dichlorvos, the highest concentration of OPPs appeared in the rivers of north China. This can be explained by the special mode of Chinese economy development. In the south China, the highly developed economy made the industry occupying the main proportion of economy total amount, the farming only occupied a small ratio. While in north China, the farming is still the main component of north China economy, OPPs had been widely used in these agriculture regions every year. The Yellow river, Huaihe river, Haihe river, and Liaohe River basins of north China were the important agricultural areas with an extremely large numbers of agricultural farmlands. OPPs used yearly on a regular basis may be a contributing factor for the elevated levels of OPPs concentrations in north China surface water. Actually, there are also several other factors affecting the occurence and persistence of OPPs in surface waters. One is the stability of the residues of the several pesticides which vary widely, another factor which will affect persistence and hence detectable amounts 
is the climatic differences from North to South, and the differences in environmental conditions between collection sites is also the factor affecting the detectable amounts and distribution. In summary, all the factors mentioned above may together result in the elevated levels of OPPs concentrations in north China surface water.

In this study, the detection rates of dimethoate, methyl parathion, malathion, and parathion were $37.0 \%, 29.7 \%$, $43.5 \%$ and $28.6 \%$, respectively, Which were all below the $50 \%$. The fact of low detection frequency for these compounds indicated that the dimethoate, methyl parathion, and malathion were not the main OPPs pollutants in Chinese surface water. When Compared with the pesticides concentrations in European freshwaters, parathion methyl was detected in the Segre (Spain), Elbe and Rhine rivers (Germany) at concentrations up to 270, $332 \mathrm{ng} / \mathrm{L}$ and $40 \mathrm{ng} / \mathrm{L}$, respectively (Planas et al. 1997; Gotz et al. 1998). Malathion was detected in River Arno (Italy), at $170.0 \mathrm{ng} / \mathrm{L}$ (Griffini et al. 1997), and dimethoate in the Elbe and Rhine rivers (Germany) at $3,210.0 \mathrm{ng} / \mathrm{L}$ and $50.0 \mathrm{ng} / \mathrm{L}$, respectively (Gotz et al. 1998). The concentrations of the dimethoate, methyl parathion, and malathion in this study were much lower, which suggested that the Chinese surface water is also somewhat moderately polluted by dimethoate, methyl parathion, malathion, and parathion. On the contrary, the detection frequency of dichlorvos and demeton was $89.1 \%, 78.2 \%$, with the mean values of $17.8 \mathrm{ng} / \mathrm{L}$ and $35.4 \mathrm{ng} / \mathrm{L}$. Compared with the dimethoate, methyl parathion, malathion, and parathion, the concentrations and frequencies of dichlorvos and demeton were much higher, which indicated that the dichlorvos and demeton were the main OPPs contaminants and the Chinese surface water was contaminated by them in certain degree.

\section{Conclusion}

This work investigated contamination status of dichlorvos, demeton, dimethoate, methyl parathion, malathion, and parathion in Chinese surface water and provided data on the levels of the six organophosphorous pesticides. In general, the measured concentrations for the six compounds were low and rarely exceed the Environment quality standard for surface water of China. For the six compounds, the dichlorvos and demeton are the major OPPs contaminants with higher detection frequency and concentration relative to the other four OPPs compounds. Comparison with other places of the world, the surface water of China was somewhat moderately contaminated by dimethoate, methyl parathion, malathion, and parathion, while the surface water in China was polluted by the dichlorvos and demeton in certain degree because of their much higher concentrations and detection frequencies. There was a significant difference in concentration between the north China and the south China surface water and the high levels of OPPs in surface water were mainly present in areas of north China. It is submit that the Yellow River basin, Huaihe River, Liaohe River, and Haihe River basins of the north China should be given priority in terms of the prevention and control of OPPs contamination.

Acknowledgments This work was supported by National Natural Science Foundation of China $(20621703 ; 20677075)$ and National Basic Research Program of China (2006CB403400;2007CB407301).

\section{References}

Christopher MT, David JS, Matthew JW (2001) Fluorinated phosphorus compounds: part 4. A lack of anticholinesterase activity for four tris (fluoroalkyl) phosphates. J Fluor Chem 107:155158. doi:10.1016/S0022-1139(00)00394-8

Eto M (1974) Organophosphorous pesticides: organic and biological chemistry. CRC, Ohio

Forney D, Davis D (1981) Effects of low concentrations of herbicides on submerged aquatic plants. Weed Sci 29:677

Fulton MH, Key PB (2001) Acetylcholinesterase inhibition in esturaine fish and invertebrates as an indicator of organophosphorus insecticide exposure and effects. Environ Toxicol Chem 20:37-45. doi:10.1897/1551-5028(2001)020<0037:AIIEFA $>2$. $0 . \mathrm{CO} ; 2$

Gotz R, Bauer OH, Friesel P, Roch K (1998) Organic trace compounds in the water of the river Elbe near Hamburg. Part II. Chemosphere 36:2103-2118. doi:10.1016/S0045-6535(98)00009-5

Griffini O, Bao ML, Barbieri C, Burrini D, Pantani F (1997) Occurrence of pesticides in the Arno river and in potable water-a survey of the period 1992-1995. B Environ Contam Toxicol 59:202-209. doi:10.1007/s001289900465

Hua XM, Shan ZJ (1999) Production, usage and environmental influence factors of pesticides in China. Sci Technol Anhui (in Chinese) 6:6-10

Huang J, Qiao F, Zhang L, Rozelle S (2000). Farm pesticides, rice production, and human health research report. Economy and Environment Program for southeast Asia

Leonard R (1988) Herbicides in surface water. In: Grover R (ed) Environmental chemistry of herbicides, vol 1. CRC, Boca Raton, pp 45-87

Miyamoto J, Mikami N, Takimoto Y (1990) The fate of pesticides in aquatic ecosystems. In: Hutson DH, Roberts TR (eds) Environmental fate of pesticides. Wiley, Chichester, pp 123-147

Mulla M, Mian L (1981) Biological and environmental impacts of insecticides malathion and parathion on non-target biota in aquatic ecosystem. Res Rev 78:101-135

Pan YH, Wei AX, Zhao GD (1997) Analysis of trace organophosphorus pesticides in water by high performance liquid chromatography/ mass spectrometry. Adv Environ Sci (in Chinese) 1:32-40

Planas C, Caixach J, Santos FJ, Rivera J (1997) Occurrence of pesticides in Spanish surface waters. Analysis by high-resolution gas chromatography coupled to mass spectrometry. Chemosphere 34:2393-2406. doi:10.1016/S0045-6535(97)00085-4

Rand GM, Wells PG, Mclarty LS (1995) Introduction to aquatic toxicology. Taylor and Francis, Washington, pp 3-66

Schulz R, Liess M (1999) A field study of the effects of agriculturally derived input on stream macroinvertebrate dynamics. Aquat Toxicol 46:155-176. doi:10.1016/S0166-445X(99)00002-8 
Shao ZR, Su F (2004) The prospect for pesticide usage in 2002 and 2003. Pestic Sci Adm (in Chinese) 25:33-35

Shelton LR (1994) Open-File Rep, U.S. Geol. Surv 94-455

Smith GJ (1987) Pesticide use and toxicity in relation to wildlife: organophosphorus and carbamate compounds. United States Department of the Interior, Fish and Wildlife Service, Resource, Washington

Tang YF, Wang YX, Cai HS (2004) Application and pollution of organophosphorous pesticides. J Wuhan Inst Chem Technol (in Chinese) 26:11-14

Zhang ZL, Hong HS, Zhou JL, Yu G, Chen WQ, Wang XH (2002a) Transport and fate of organochlorine pesticides in River Wuchuan, southeast China. J Environ Monit 4:435-441. doi:10.1039/ b111204j

Zhang ZL, Dai MH, Hong HS, Zhou JL, Yu G (2002b) Dissolved insecticides and polychlorinated biphenyls in the Pearl River Estuary and South China Sea. J Environ Monitor 4:922-928. doi: $10.1039 / \mathrm{b} 206891 \mathrm{p}$

Zhou JL, Hong HS, Zhang ZL, Maskaoui K, Chen WQ (2002) Multiphase distribution of organic micropollutants in Xiamen Harbour, China. Water Res 34:2132-2150. doi:10.1016/S0043-1354(99) 00360-7 